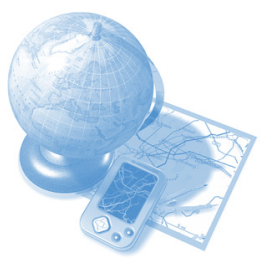

Stephen P Stanforth School of Applied Sciences

Northumbria University Newcastle upon Tyne NE1 8ST steven.stanforth@ unn.ac.uk

\section{Development of an open-learning module in natural product chemistry}

\begin{abstract}
This article describes the author's personal perspective on the design, production and delivery of an open-learning module in natural product chemistry. This 10 credit, level 6 module is delivered using three tutorial sessions and is assessed by three open-book tests. The study material is available to the students as both hard-copy and electronic copy.
\end{abstract}

\section{Introduction}

The School of Applied Sciences, Northumbria University has a long tradition in providing part-time day release courses at both HNC and BSc levels, and offering Sandwich placements to full-time students. As a former Polytechnic, there has always been this strong vocational aspect to the School's chemistry-based courses.

In 1998, the School was considering introducing an MChem course, possibly with a sandwich element. Part of the sandwich year would have required the student to study a number of modules while on placement and consequently the author began to consider writing a suitable 'distance learning' module. An additional reason for producing such a module was that it might also become available for part-time BSc students. Students attend the School's part-time BSc course one day plus evening per week. The distance a student lives from the University often dictates whether attendance on the part-time BSc course is viable. If the amount of time spent at the University were to be reduced through the provision of some distance learning modules, then this might make the part-time BSc degree more attractive to students who have long distances to travel and also to many of our part-time students who have family and other commitments.

Although it began as a distance learning module, once the unit had been written it was apparent that it could also be used by full-time BSc students. Thus, the final product is best described as an open-learning module.

One of the problems associated with writing distance or open-learning modules is finding the time to produce the material. Fortunately, development project funding was provided through 'Project Improve' (whose work is now continued through the Higher Education Academy Physical Sciences Centre $)^{1}$.

\section{Considerations in module design}

The author wished to produce a module suitable for study by final year undergraduate students. Natural product chemistry was chosen for the subject matter because:

- It could be used to reinforce the basic organic chemistry taught in the first and second years of the degree course, principally carbanion chemistry, carbo-cation chemistry, free-radical chemistry, alkylations, oxidations, reductions. Thus, students would be able to apply their existing knowledge, understanding and skills in organic chemistry to new situations.

- It would introduce the student to the biosynthetic principles used by nature to produce a range of natural products and hence students would be able to appreciate organic chemistry in a wider context.

- The module could be extended in the future to cover additional areas of natural product chemistry eg NMR spectroscopy for elucidation of biosynthetic pathways, methods used for the isolation of natural products, the medicinal chemistry associated with natural products etc - subject areas that are not at present covered by the module.

- The module might be extended in the future to cover some additional areas either at the same level to produce a double module, or at a higher eg MSc level to produce a follow-on module. 
- The module would be useful to other Universities. Part of the conditions for 'Project Improve' funding was to make the material produced freely available. Other Universities could choose whether to use the module as it stands, supplement it with additional areas, expand existing areas etc.

In writing the unit, the author consulted and used as far as possible the excellent article on designing independent learning material by Dr Stuart Bennett ${ }^{2}$.

\section{Module structure}

The module was written in five chapters ${ }^{3}$. These were: Chapter A. Acetyl coenzyme A: a key biological intermediate Chapter B. Biosynthesis of fatty acids

Chapter C. Biosynthesis of polyketides

Chapter D. Shikimic acid pathway and alkaloid biosynthesis Chapter E. Terpenes

At the beginning of each chapter there are a list of objectives (learning outcomes) that the student is expected to achieve. There is also an indication of the prior learning a student will need to have in order to appreciate and understand the principles that are being introduced. All chapters have been broken down into of a number of relatively short sections to facilitate digestion of the material. Problems, with solutions, are included at regular intervals to enable the student to test understanding and to provide formative self-assessment. The underlying chemical principles in each chapter are related to familiar organic chemical reactions wherever possible in order to demonstrate the common underlying principles between biosynthesis and organic chemistry. Each chapter concludes with a summary of key points and a further reading list.

The comments and suggestions received from colleagues on the first draft resulted in minor alterations in the final version. The hard-copy was then transformed by the author into a website to enable ready access to the material by other Institutions. The hard-copy version and the web-site have identical content.

In retrospect, the module would probably best have been titled 'Natural Product Biosynthesis' but the broader name 'Natural Product Chemistry' has been retained to allow for further expansion of the work.

\section{Delivery of the module}

The Natural Product Chemistry module has been running at Northumbria since 1998. It is used predominantly as a semester long optional module (10 level 6 credits) for the School's full and part-time final year degree students and is therefore best described as an open-learning module because the students are in attendance. Typical group sizes are 10-15 students. It has however also been used on several occasions as a true distance learning module for part-time students who have moved away from the region, generally through work commitments.

At the start of the module there is a short introductory session in which the students receive a hard-copy booklet and the organisation and assessment strategy of the module is explained. The module is delivered through three, one-hour tutorial sessions. The students are given a number of problems in advance of each tutorial session and they are expected to attempt these before they attend the tutorial (see appendix A). These problems also allow the students to engage in formative assessment. The first tutorial covers material from chapter $A$, the second tutorial covers material from chapters $B$ and $C$ and the third tutorial covers work from chapters D and E. During the tutorial sessions, students are expected to explain their solutions to the problems to their peers and thus actively engage with the work rather than passively receive solutions to problems. The tutor also summarises the key principles introduced in each chapter during the tutorial sessions and will also answer any questions.

\section{Assessment of the module}

The module is assessed by three one-hour open-book tests (see appendix B) corresponding to the tutorial division. Each open-book test consists of six short questions and takes place the week after the corresponding tutorial. The average mark for the module is generally in the high 50 s - low 60 s ie comparable with other optional modules that have formal end examinations. In cases where part-time students have been unable to attend the tests, the tests have been e-mailed or sent as hard-copy to employers who have invigilated the test and then returned the scripts.

\section{Student Feedback}

Feedback from the module has been extremely positive. Students have commented that they can work at their own pace and the module is much more flexible than traditionally taught modules. They also like the tutorial style and the use of open-book tests as summative assessments. Many full-time students have commented that because of substantial parttime work commitments, open-learning has enabled them to manage their time more flexibly. Part-time students who study day and evening have commented that open-learning is a welcome break from the traditional routine of lectures and laboratories throughout the day.

\section{Summary}

Preparing the material for the Natural Product Chemistry open-learning module was time intensive but the rewards have been excellent. It has made students responsible for their own learning and has enabled some students to complete the module successfully without attendance at the University. The tutorial style of delivery and assessment by open-book tests has proved tremendously popular with the tutor and the students. The School's external examiners have also commented favourably on the style and delivery of this module. I hope colleagues at other Institutions are able to make use of this resource.

\section{References}

1. http://www.physsci.heacademy.ac.uk/Home/lndex.aspx

2. http://www.physsci.heacademy.ac.uk/Publications/ PracticeGuide/guide3.pdf

3. http://www.nl-webspace.co.uk/ unn_chss1/

\section{Acknowledgements}

The author would like to thank 'Project Improve' for funding the development of this module and colleagues who have provided useful feedback and suggestions on the module's design and content. 


\section{Appendix A}

An example of a set of tutorial questions. The questions below relate to Chapter $A$.

\section{Tutorial 1}

1. If labelled acetate ${ }^{*} \mathrm{CH}_{3} \mathrm{CO}_{2}{ }^{-}\left({ }^{*}={ }^{14} \mathrm{C}\right)$ was used in the biosynthesis of stearic acid, at which positions would you expect the labelled carbon atoms to appear ?

2. You are unsure whether the methyl group in tuberculostearic acid is derived from propionate or S-adenoyl methionine. Suggest a suitable labelling experiment which might resolve this. Write a mechanism for this reduction. Show how the ester 3 might therefore be biosynthesized from appropriate thioester and alcohol precursors.

4. The stereochemistry of the elimination of water from thioester $\mathbf{4}$ giving the alkene $\mathbf{5}$ is shown below. Is the elimination of water a syn or anti elimination?
3. Thioesters $\mathbf{1}$ can be reduced to alcohols $\mathbf{2}$ by NADH.<smiles>CCCSC(=O)CCC</smiles>

1<smiles>[B]SC(=O)C([CH])([Hg])C(C)O</smiles>

4

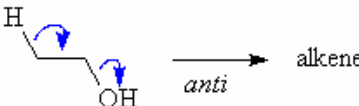<smiles>CCCCO</smiles><smiles>CCCCOC(=O)CCC</smiles>

\section{Appendix B}

An example of a set of open-book questions. These questions relate to Chapters $B$ and $C$ (polyketides and shikimic acid).

\section{CH335 Natural Product Chemistry \\ Module Open Book Test Number 2}

Name:

\section{Grade: A B C D E F}

Time allowed: 1 hour

Answer all questions (all questions 5 marks; 30 marks in total - a preliminary grade will be awarded. Marks may be subject to moderation by the examination board)<smiles>CCCCC(=O)CC(=O)CC(=O)CC(=O)CC(=O)CC(C)C</smiles><smiles>COc1cc(O)c2c(=O)c3c(C)cc(O)cc3oc2c1</smiles>

1. Propose a reasonable biosynthesis of Grieseoxanthone C 2 from the polyketide 1 .<smiles>CCCCC(=O)CC(=O)CC(=O)CC(=O)c1ccccc1N</smiles>

3<smiles>COc1cc2c(c(O)c1OC)c(=O)c1ccccc1n2C</smiles>

4
2. Show how the polyketide $\mathbf{3}$ might be converted into Aborinine 4. have been biosynthesised from the starter unit $\mathbf{5}$.<smiles>CCCCSC(=O)c1ccccc1N</smiles>

5

4. Compound $\mathbf{7}$ is an intermediate in the biosynthesis of the indole derivative 8 from phenylalanine 6 . Propose a reasonable biosynthesis of compound 7 from phenylalanine 6.<smiles>NC(Cc1ccccc1)C(=O)O</smiles><smiles>O=C(O)c1cc2cc(O)c(O)cc2[nH]1</smiles>

5. Show how Reticuline $\mathbf{9}$ might be converted into Coryuberine 10 via phenoxy radical intermediates.<smiles>COc1ccc(CC2c3cc(O)c(OC)cc3CCN2C)cc1O</smiles>

9<smiles>COc1ccc2c(c1O)-c1c(O)c(OC)cc3c1C(C2)N(C)CC3</smiles>

10
6. If labelled acetate, where the label is on the methyl carbon atom, was used in the biosynthesis of compounds 2 and $\mathbf{4}$, indicate on structures 2 and $\mathbf{4}$ (with an *) the positions at which you would expect to find the labels.
3. Show how polyketide $\mathbf{3}$ might<smiles>NC(CC1=CC(=O)C(=O)C=C1)C(=O)O</smiles> 